\title{
Apomorphine in idiopathic restless legs syndrome: an exploratory study
}

\author{
G G Tribl, T Sycha, N Kotzailias, J Zeitlhofer, E Auff
}

J Neurol Neurosurg Psychiatry 2005;76:181-185. doi: 10.1136/jnnp.2003.034843

See end of article for authors' affiliations

.....................

Correspondence to: Dr Gotthard G Tribl, Department of Neurology, University of Vienna,

Vienna General Hospital Waehringer Guertel 1820, A-1097 Vienna Austria; gotthard.tribl@ meduniwien.ac.at

Received

18 December 2003

In revised form

11 May 2004

Accepted 31 May 2004
Background: Dopaminergic and opioidergic drugs have been found to be effective in patients with restless legs syndrome (RLS).

Objectives: To test the effect of apomorphine-a combined opioidergic and dopaminergic agonist-and subsequent selective antagonism by naloxone and metoclopramide on subjective and objective symptoms in patients with idiopathic RLS.

Methods: Nine patients with RLS were pretreated with oral domperidone for three days. A modified suggested immobilisation test (SIT) was carried out between $8 \mathrm{pm}$ and 1 am under the following conditions of intravenous drug administration: baseline-apomorphine-apomorphine plus naloxone-apomorphine plus metoclopramide. Outcome variables were a visual analogue scale (VAS) of subjective RLS symptoms and EMG documented periodic leg movements while awake (PLMW).

Results: Compared with baseline, apomorphine resulted in a rapid and significant improvement in subjective RLS symptoms as measured by VAS (54.5\% improvement; $p=0.011$ ), and an almost immediate cessation of PLMW, measured by PLMW index (98.0\% improvement; $p=0.012)$. Neither additional naloxone nor metoclopramide blocked this effect significantly. While given apomorphine with metoclopramide, there was a trend to reappearance of PLMW.

Conclusions: Apomorphine may be an effective treatment for idiopathic RLS. Its effectiveness may reflect both to its dopaminergic and its opioidergic activity, and is not diminished significantly by blocking only one of these pathways. The trend to a worsening of the PLMW index with metoclopramide hints at a primarily dopaminergic effect of apomorphine in idiopathic RLS.
$\mathrm{T}$ he prevalence of the restless legs syndrome (RLS) is around $10 \%$ in Western populations. ${ }^{1-5}$ It is defined by four essential diagnostic criteria ${ }^{6}$ : an urge to move the legs, usually accompanied by uncomfortable and unpleasant sensations in the legs; worsening during inactivity; improvement with movements; and worsening in the evening or at night. Further clinical features are a positive family history, a response to dopaminergic drugs, periodic limb movements during wakefulness (PLMW) or sleep (PLMS), sleep disturbances, and a normal neurological examination.

Therapeutic effects of L-dopa, dopamine agonists, and different opioidergic substances on RLS symptoms have been demonstrated. ${ }^{7}$ Dopaminergic treatment is considered to be most effective. ${ }^{8}$ A reduction in PLMS has been documented in RLS patients during dopaminergic treatment. ${ }^{9-12}$

Involvement of the opioidergic and dopaminergic systems in RLS has been demonstrated. Naloxone, an opioid antagonist, which acts at all three types of opioid receptors $(\mu, \kappa$, and $\sigma)$, antagonised the treatment effects of propoxyphene and methadone in two patients ${ }^{13}{ }^{14}$; pimozide, a D2 receptor antagonist, partially antagonised the treatment effect of codeine sulphate in a further patient. ${ }^{15}$ D2 receptor antagonists such as olanzapine ${ }^{16}$ and risperidone ${ }^{17}$ are suspected to provoke RLS. However, in untreated patients, intravenous administration of the opioid antagonist naloxone and the D2 receptor antagonist metoclopramide failed to cause deterioration in the sensory or motor symptoms of RLS. $^{18}$

Apomorphine (10,11-dihydroxyaporphine), a derivative of morphine, acts as a dopamine and opioid agonist. It has a good D2, D3, and D4 receptor affinity and much less affinity for D1 and D5 receptors. ${ }^{19}$ The ratio of its affinity for D2 to its affinity for D1 is about 10:1. Metoclopramide can antagonise apomorphine induced stereotypy in rats. ${ }^{20}$ Naloxone is known to reverse the opioidergic effects of high doses of apomorphine, such as central nervous system and respiratory depression. $^{21}$

There are only a few case reports on apomorphine in RLS. In one patient with idiopathic RLS and another with Parkinson's disease and RLS, an overnight infusion of apomorphine improved nocturnal discomfort and leg movements. Periodic limb movements were not assessed. ${ }^{22}$ Another patient with paraspastic symptoms and a vitamin B-12 deficiency induced PLM disorder had an EMG documented response to subcutaneous apomorphine. ${ }^{23}$ In nine patients with a periodic limb movement disorder, $0.5 \mathrm{mg}$ of subcutaneous apomorphine at bedtime resulted a significant reduction of PLMS during the first four hours of sleep compared with two control nights. ${ }^{24}$ Eight patients from that study were reported also to have RLS; however, the RLS was not clinically characterised nor were apomorphine effects measured..$^{24}$ In a sample of 12 parkinsonian patients, one night's treatment with apomorphine improved akinesia, rigidity, and sleep indices, ${ }^{25}$ including a $15 \%$ reduction in the periodic limb movement index. RLS symptoms were not documented.

As data are scarce, we carried out this study in order to document the effects of apomorphine in idiopathic RLS. We hypothesised that apomorphine might be effective in people suffering from this condition. We also investigated whether the effects of apomorphine on subjective and objective RLS

\footnotetext{
Abbreviations: IRLSSG, International RLS Study Group; PET, positron emission tomography; PLMS, periodic limb movements during sleep; PLMW, periodic limb movements during wakefulness; RLS, restless legs syndrome; SIT, suggested immobilisation test; SPECT, single photon emission computed tomography; VAS, visual analogue scale
} 
symptoms could be reversed by selective opioidergic or dopaminergic antagonism.

\section{METHODS}

\section{Subjects}

This study was approved by the local ethics committee and written informed consent was obtained from all participants before study entry.

Nine consecutive patients with severe idiopathic RLS (five male/four female; mean (SEM) age, 55.3 (3.1) years; tables 1 and 2) were included in a prospective, open, observational study. Six patients were pretreated and had responded to specific treatment (table 2) but were still suffering from RLS symptoms. Three patients were drug-naive.

Inclusion criteria were: men or women aged between 30 and 75 years, with severe and almost daily (six or seven days a week) restless leg symptoms according to the definition of the International RLS Study Group (IRLSSG). ${ }^{6}$ There were normal findings in the medical history, physical and neurological examination, and blood analyses, and objective sleep disturbances were documented on whole night polysomnography. The PLMS index was $>10$ per hour of total sleep time. Subjective sleep and daytime sleepiness were controlled by the Pittsburgh sleep quality index ${ }^{26}$ and the Epworth sleepiness scale. ${ }^{27}$

Exclusion criteria were as follows:

- any secondary RLS (for example, from renal insufficiency-excluded by serum creatinine and blood urea nitrogen);

- disorders of iron metabolism (excluded by measurements of iron, ferritin, and transferrin);

- diabetes mellitus (excluded by measurement of serum glucose and HbAlc);

- thyroid dysfunction (excluded by measurements of TSH, $\mathrm{T} 3$, and $\mathrm{T} 4)$;

- anaemia (excluded by blood count);

- deficiency of folic acid, vitamin B-12, or magnesium (all within the normal range);

- pregnancy;

- signs of a severe polyneuropathy on clinical examination or in the nerve conduction velocity studies;

- any other sleep disorder;

- an apnoea index of $>5 /$ hour total sleep time or an apnoeahypopnoea index of $>10$ /hour total sleep time;

- any previous intake of neuroleptic agents or any intake of other psychotropic drugs during the previous six months;

- alcohol abuse.

Table 1 Clinical characteristics of nine patients with idiopathic restless legs syndrome

\begin{tabular}{lll}
\hline Variable & Mean (SEM) or $\mathbf{n}$ & Range \\
\hline M/F & $5 / 4$ & \\
Age (years) & $55.3(3.1)$ & $(41$ to 71$)$ \\
PSQI & $11.9(1.5)$ & $(4$ to 19$)$ \\
ESS & $6.2(1.2)$ & $(0$ to 12$)$ \\
Duration of RLS (years) & $16.3(3.9)$ & $(3$ to 40$)$ \\
IRSSG rating scale & $27.1(2.2)$ & $(15$ to 37$)$ \\
PLMS/h TST & $32.1(8.2)$ & $(10.1$ to 91.9$)$ \\
Sleep efficiency (TST/TIB) (\%) & $72.4(5.0)$ & (40.1 to 85.7) \\
\hline
\end{tabular}

ESS, Epworth sleepiness scale (daytime sleepiness); IRLSSG, International RLS Study Group rating scale; PLMS/h TST, periodic leg movement index per hour total sleep time; PSQI, Pittsburgh sleep quality index; RLS, restless legs syndrome; TST/TIB: total sleep time/time in bed (sleep efficiency).
In the pretreated patients, specific drug treatment was discontinued at least 10 times the plasma half life before the study day. One patient treated with ropinirole (half life 5.8 hours $^{28}$ ) could not tolerate the drug withdrawal and discontinued the treatment 48 hours before the study. Apomorphine is known to cause effects such as nausea, drowsiness, sedation, and arterial hypotension. ${ }^{29}$ To prevent these possible side effects, domperidone $(30 \mathrm{mg}$ three times daily) - a potent peripheral dopamine antagonist which does not cross the blood-brain barrier ${ }^{30}$ - was given orally three days before the study.

\section{Study procedure}

The patients arrived at the sleep centre for baseline RLS symptom assessments and mounting of electrodes at 7.00 pm. Electrodes for electroencephalography, electro-oculography, and surface electromyography of both mental muscles and both anterior tibial muscles were set up. Non-invasive surface electrodes were placed over the belly of both anterior tibial muscles, 2 to $4 \mathrm{~cm}$ apart on the long axis of the muscles. An impedance of less than $10000 \mathrm{ohm}$ was set. Band pass filter settings of $10 \mathrm{~Hz}$ and $90 \mathrm{~Hz}$ with a time constant of 0.003 seconds were used. An intravenous cannula was mounted in the cubital vein

A modified suggested immobilisation test $(\text { SIT })^{931}{ }^{32}$ was carried out. The patients lay in bed in the supine position with the upper body slightly raised at a $45^{\circ}$ angle. They were advised to limit their voluntary movements for the entire duration of the test and not to fall asleep. If they did so, they were awakened. Every five minutes during the SIT, the patients were asked to rate their subjective leg symptoms (subjective leg dysaesthesias and the need to move the legs) by means of an 11 point (0-10) visual analogue scale (VAS). ${ }^{33}$ SIT data were recorded on a personal computer system (Alpha-trace; Grossegger, Vienna, Austria). Periodic limb movement scoring was done automatically and visually. Scoring rules followed international recommendations:

- a "leg movement" is a burst of the anterior tibial muscle activity lasting 0.5 to 5 seconds and with an amplitude greater than $25 \%$ of calibration ( = toe movement without resistance);

- a "PLM sequence" is a sequence of four or more periodic leg movements separated by at least 4 but not more than 90 seconds. ${ }^{34} 35$

According to recent SIT studies, which showed a longer duration of periodic leg movements during wakefulness than in sleep, we used a duration criterion of 0.5 to 10.0 seconds for leg movements. ${ }^{32}$

The SIT started at $8 \mathrm{pm}$. All study drugs were given intravenously. Each of the four conditions (baseline, apomorphine, apomorphine plus naloxone, apomorphine plus metoclopramide) was measured for 30 minutes. Mean values of the five minute VAS values were calculated. The number of PLMW was doubled to determine the PLMW index per hour. Baseline condition was measured after the patients had reached their subjective typical RLS discomfort. Subsequently, apomorphine was given as a bolus of $0.035 \mathrm{mg} / \mathrm{kg}$ body weight and continuously as an intravenous infusion in a dose of $0.03 \mathrm{mg} / \mathrm{kg} / \mathrm{h}$. According to clinical response, the dose was increased (or decreased) by $0.01 \mathrm{mg} / \mathrm{kg} / \mathrm{h}$ every 15 minutes until there was a stable clinical effect on RLS symptoms, at which point VAS and PLMW were measured. The dose in the final step was then given continuously for the rest of the SIT. Naloxone was given as a $2 \mathrm{mg}$ bolus in all patients; metoclopramide was administered as a bolus of $2 \mathrm{mg} / \mathrm{kg}$ body weight. The effect of naloxone was measured immediately after administration. There was then a 30 minute 
Table 2 Clinical details of nine patients with idiopathic restless legs syndrome (RLS)

\begin{tabular}{|c|c|c|c|c|c|c|c|}
\hline & Sex & Age (years) & $\begin{array}{l}\text { Duration of RLS } \\
\text { (years) }\end{array}$ & Family history* & " PNP*广 & Specific drug treatment $(\mathrm{mg} / \mathrm{d})$ & Other drugs $(\mathrm{mg} / \mathrm{d})$ \\
\hline 1 & $\mathrm{~F}$ & 58 & 12 & + & - & $\begin{array}{l}\text { L-dopa } 200 \mathrm{mg} \\
\text { CR+benserazide } 50 \mathrm{mg}\end{array}$ & Candesartan $4 \mathrm{mg}$ \\
\hline 2 & $\mathrm{~F}$ & 56 & 8 & - & - & Gabapentin 900 mg & $\begin{array}{l}\text { Indapamide } 1.5 \mathrm{mg} \\
\text { Diosmin } 900 \mathrm{mg}\end{array}$ \\
\hline 3 & M & 55 & 30 & - & + & Gabapentin 900 mg & $\begin{array}{l}\text { Phenprocoumon } \\
\text { Losartan } 12.5 \mathrm{mg} \\
\text { Doxazosin } 1 \mathrm{mg} \\
\text { Salbutamol }\end{array}$ \\
\hline 4 & $\mathrm{~F}$ & 41 & 12 & - & - & $\begin{array}{l}\text { L-dopa } 200 \mathrm{mg} \\
\text { L-dopa } 200 \mathrm{mg} \text { CR } \\
\text { +benserazide } 100 \mathrm{mg}\end{array}$ & 0 \\
\hline 5 & M & 51 & 9 & - & + & $\begin{array}{l}\text { Gabapentin } 400 \mathrm{mg} \\
\text { Alprazolam } 0.25 \mathrm{mg}\end{array}$ & 0 \\
\hline 6 & M & 65 & 40 & + & + & Ropinirole $1 \mathrm{mg}$ & 0 \\
\hline 7 & M & 45 & 16 & - & + & Drug-naive & 0 \\
\hline 8 & M & 71 & 3 & - & - & Drug-naive & $\begin{array}{l}\text { Metoprolol } 23.8 \mathrm{mg} \\
\text { Aspirin } 100 \mathrm{mg} \\
\text { Oxerutin } 300 \mathrm{mg}\end{array}$ \\
\hline 9 & $\mathrm{~F}$ & 56 & 17 & - & - & Drug-naive & 0 \\
\hline
\end{tabular}

washout period. After administration of metoclopramide, there was a half hour wait before the clinical effect was measured. The duration of the entire SIT ranged between three hours and four hours, 14 minutes.

\section{Statistical analysis}

Expecting a non-normal distribution in the small sample size of nine participants, non-parametric statistics were used. Comparisons of treatment effects were analysed with the Wilcoxon matched pairs test. The Friedman ANOVA (analysis of variance) was used as a test statistic for the treatment effect over time. The level of significance was set at $\mathrm{p}<0.05$. Baseline values are described as mean (SEM), and treatment effects as percentage change from baseline. Because of the exploratory character of the study and the small sample size, even borderline significant results were interpreted.

\section{RESULTS}

\section{VAS of subjective leg symptoms}

The VAS results for subjective leg symptoms (subjective leg dysaesthesiae and the need to move the legs) are shown in table 3 and fig 1 .

The baseline mean (SEM) VAS symptom score was 5.8 (0.7), which was reduced by apomorphine by $54.5 \%$ $(\mathrm{p}=0.011)$. Compared with baseline, apomorphine plus naloxone reduced mean VAS by $46.4 \%(\mathrm{p}=0.015)$ and apomorphine plus metoclopramide reduced it by $41.7 \%$ $(p=0.028)$. Compared with apomorphine alone, naloxone with apomorphine and metoclopramide with apomorphine increased mean VAS non-significantly (by $8.1 \%$ and $12.9 \%$ ).

\section{PLMW index}

The results of the PLMW index (number of periodic leg movements during wakefulness per hour of the SIT) are shown in table 3 and fig 1.

The baseline mean PLMW index was 56.4 (19.2). Apomorphine reduced this by $98.0 \%(p=0.012)$. Compared with baseline, apomorphine plus naloxone reduced the index by $98.4 \%(p=0.012)$ and apomorphine plus metoclopramide reduced it by $74.8 \%(\mathrm{p}=0.058)$. Compared with apomorphine alone, naloxone plus apomorphine decreased the index by $0.4 \%$ (NS) and metoclopramide plus apomorphine increased it by $23.2 \%$ (NS).

\section{Latency, effective dosage, and side effects of apomorphine}

The treatment effects of apomorphine were reached very rapidly. The mean latency to reach a stable and significant improvement was 13.1 (3.5) minutes for subjective leg discomfort and 5.1 (1.7) minutes for the PLMW. Effective doses of apomorphine were reached in seven of the nine participants with the initial bolus of $0.035 \mathrm{mg} / \mathrm{kg}$ body weight or with a constant infusion rate of up to $0.04 \mathrm{mg} / \mathrm{kg} / \mathrm{h}$. One patient (No 5) needed $0.05 \mathrm{mg} / \mathrm{kg} / \mathrm{h}$ of apomorphine for adequate response. This patient had shown a poor response to previous dopaminergic treatment (L-dopa with benserazide and cabergoline). Another drug-naive patient (No 9) with a high PLMS index (40.2/h TST) needed $0.07 \mathrm{mg} / \mathrm{kg} / \mathrm{h}$ of apomorphine for adequate response.

After the initial bolus of apomorphine, side effects were frequent and in a few patients they were marked, as follows (cumulative numbers of affected patients in brackets):

Table 3 Results from nine patients with idiopathic restless legs syndrome

\begin{tabular}{|c|c|c|c|c|c|c|}
\hline & \multicolumn{3}{|l|}{ VAS } & \multicolumn{3}{|l|}{ PLMW/h } \\
\hline & Mean (SEM) & $\begin{array}{l}\text { Relative reduction } \\
\text { of symptoms }(\%)\end{array}$ & $\mathrm{p}$ Value ( $v$ baseline) & Mean (SEM) & $\begin{array}{l}\text { Relative reduction } \\
\text { of symptoms }(\%)\end{array}$ & $p$ Value ( $v$ baseline) \\
\hline Baseline & $5.8(0.7)$ & - & - & $56.4(19.2)$ & - & - \\
\hline Apomorphine & $2.6(0.8)$ & -54.5 & 0.011 & $1.1(1.1)$ & -98.0 & 0.012 \\
\hline Apomorphine + naloxone & $3.1(0.8)$ & -46.4 & 0.015 & $0.9(0.6)$ & -98.4 & 0.012 \\
\hline $\begin{array}{l}\text { Apomorphine + } \\
\text { metoclopramide }\end{array}$ & $3.4(0.8)$ & -41.7 & 0.028 & $14.2(8.3)$ & -74.8 & 0.058 \\
\hline
\end{tabular}

Values are given as mean (SEM) and relative reduction of symptoms as compared with baseline. Visual analogue sale (VAS) and periodic leg movements per hour (PLMW/h) under the four conditions of baseline, apomorphine, apomorphine + naloxone, and apomorphine + metoclopramide. 

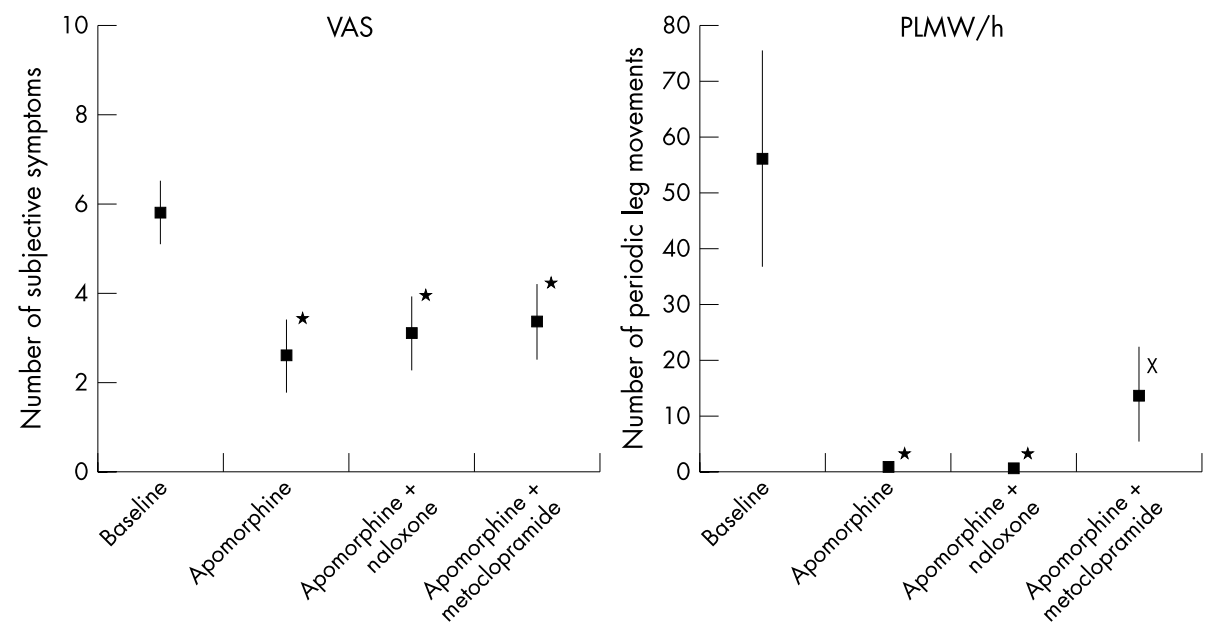

Figure 1 Subjective leg symptoms (visual analogue scale) and periodic leg movements during wakefulness per hour (PLMW/h) during the immobilisation test in nine patients with idiopathic restless legs syndrome. ${ }^{*} p<0.05 v$ baseline; ${ }^{\times} \mathrm{NS} v$ baseline.

drowsiness (8), yawning (7), dizziness (6), falling asleep (4), severe nausea (4), coughing (4), sweating (4), nasal congestion (3), lacrimation (2), heat sensation (2), mild nausea (2), hiccup (1), vomiting (1), diarrhoea (1), mild hyperventilation (1), slight hoarseness (1), chills (1). In the steady state of apomorphine administration, side effects were less marked. Naloxone improved CNS side effects such as drowsiness and dizziness to some extent. Metoclopramide improved gastrointestinal side effects rapidly, especially nausea, which was fully reversed.

\section{DISCUSSION}

The main finding of this study was that apomorphine caused a rapid and highly significant improvement in subjective symptoms and periodic limb movements during wakefulness, even in this small group of nine patients with idiopathic RLS. Neither naloxone nor metoclopramide antagonised this effect to a significant extent. Given the exploratory character of the study, apomorphine may therefore be considered effective in idiopathic RLS.

Naloxone had no significant impact on the effect of apomorphine. Hence, blocking of $\mu, \kappa$, or $\sigma$ receptors of the opioidergic system does not seem to influence the apomorphine effect in idiopathic RLS.

The combined administration of apomorphine plus metoclopramide compared with apomorphine alone and with apomorphine plus naloxone produced no significant difference in the subjective RLS symptoms or the PLMW index. Comparing combined apomorphine plus metoclopramide administration with baseline, the improvement in RLS symptoms was significant, but there was only a trend to improvement of the PLMW index. There could be various reasons for this finding. First, in a previous study it was shown that both subjective symptoms on the VAS and periodic limb movements increased in patients with RLS during the SIT. After 10 minutes of SIT, both variables differed significantly in patients compared with healthy controls. ${ }^{36}$ In our study, metoclopramide was given after two to three hours of SIT, so an increase in RLS symptoms might reflect the long duration of the SIT. However, at the time of administration of naloxone, after a SIT duration of at least one hour, there was only a slight increase in leg discomfort and no increase in PLMW. Another explanation for our findings might be partial blockade of the apomorphine effect by the $\mathrm{D} 2$ receptor antagonist metoclopramide, causing the non-significant reappearance of PLMW. This could be interpreted as a primarily dopaminergic mechanism in idiopathic
RLS. ${ }^{15}$ Furthermore, our results support the recommendation to use dopaminergic substances as first line treatment, and opioidergic substances as second line treatment in RLS. ${ }^{8}$ Owing to the small numbers in our sample, the antagonising effect of metoclopramide might not have reached statistical significance, but the results encourage further studies on a possible antagonism of apomorphine and metoclopramide in RLS.

Dopaminergic pathways in the CNS have been examined in different functional imaging studies. SPECT and PET studies of the dopaminergic synapse in the striatum produced equivocal results. Some groups reported presynaptic ${ }^{37} 38$ or postsynaptic ${ }^{37}{ }^{39-41}$ alterations. However, in all these studies the differences were only small. ${ }^{42}$ In contrast, some studies have shown normal functional conditions at the dopaminergic synapse in RLS. ${ }^{43-45}$ The useful effects of apomorphine in our patients are in accord with many treatment studies with dopaminergic and opioidergic substances, ${ }^{7}$ but the location of action of apomorphine in RLS remains unknown.

In our patients, some side effects of apomorphine were accentuated. In evaluating a possible therapeutic use of apomorphine in RLS, one should bear in mind that our patients were receiving apomorphine for the first time and that the dose escalation was rapid. Seven of the nine patients had good and stable improvement in their symptoms with the initial dose, which encourages trials of lower doses. Generally, effective long term treatment dosages of L-dopa and dopamine agonists are lower in RLS than in Parkinson's disease. In RLS, a slower tapering of apomorphine to a lower therapeutic dose might be better tolerated but still effective.

In the present study we needed an intravenous route for the administration of naloxone and metoclopramide. Apomorphine was also given intravenously, because we did not want to expose the participants to any further unnecessary risk, such as subcutaneous reactions (panniculitis) to apomorphine. ${ }^{46}$ However, apomorphine given subcutaneously in similar doses to those we used intravenously have been reported to be well tolerated in the long term treatment of advanced Parkinson's disease, ${ }^{47}{ }^{48}$ and this might also be a possible way of giving the drug in RLS. The pharmacokinetics (drug absorption, volume of distribution, plasma clearance, and half life) of intravenously and subcutaneously administered apomorphine are similar. ${ }^{49}$ An equally good effect of subcutaneous apomorphine in RLS may be assumed. Transdermal administration of apomorphine has also been considered in Parkinson's disease with periodic leg movements ${ }^{25}$ and might be a further option in the treatment of 
RLS. Oral dopamine agonists remain the first line treatment in RLS. However, apomorphine could be helpful in severe, treatment refractory, and well selected cases.

Furthermore, a modified "apomorphine test" might be used as a diagnostic tool in RLS. This test is established for the rapid evaluation of the dopaminergic response in parkinsonian syndromes, ${ }^{50}$ and might be used in patients with suspected RLS both for diagnostic purposes and for the evaluation of a possible therapeutic response. Thirty minutes of apomorphine administration under SIT conditions should be sufficient to evaluate an eventual response.

\section{Authors' affiliations}

G G Tribl, T Sycha, N Kotzailias, J Zeitlhofer, E Auff, Department of Neurology, University of Vienna, Vienna, Austria

Competing interests: none declared

\section{REFERENCES}

1 Lavigne GJ, Montplaisir JY. Restless legs syndrome and sleep bruxism: prevalence and association among Canadians. Sleep 1994;17:739-43.

2 Phillips B, Young T, Finn L, et al. Epidemiology of restless legs symptoms in adults. Arch Intern Med, 2000;160:2137-41.

3 Rothdach AJ, Trenkwalder C, Haberstock J, et al. Prevalence and risk factors of RLS in an elderly population: the MEMO study. Memory and Morbidity in Augsburg Elderly. Neurology 2000;54:1064-8.

4 Ulfberg J, Nystrom B, Carter N, et al. Prevalence of restless legs syndrome among men aged 18 to 64 years: an association with somatic disease and neuropsychiatric symptoms. Mov Disord 2001;16:1159-63.

5 Ulfberg J, Nystrom B, Carter N, et al. Restless legs syndrome among workingaged women. Eur Neurol $2001 ; 46: 17-19$.

6 Allen RP, Picchietti D, Hening W, et al. Restless legs syndrome: diagnostic criteria, special considerations, and epidemiology. A report from the restless legs syndrome diagnosis and epidemiology workshop at the National Institutes of Health. Sleep Med 2003:4:101-19.

7 Hening W, Allen R, Earley C, et al. The treatment of restless legs syndrome and periodic limb movement disorder. An American Academy of Sleep Medicine review. Sleep 1999;22:970-99.

8 Chesson AL, Wise M, Davila $D$, et al. Practice parameters for the treatment of restless legs syndrome and periodic limb movement disorder. An American Academy of Sleep Medicine Report. Standards of Practice Committee of the American Academy of Sleep Medicine. Sleep 1999;22:961-8.

9 Brodeur C, Montplaisir J, Godbout R, et al. Treatment of restless legs syndrome and periodic movements during sleep with L-dopa: a double-blind, controlled study. Neurology 1988;38:1845-8.

10 Kaplan PW, Allen RP, Buchholz DW, et al. A double-blind, placebo-controlled study of the treatment of periodic limb movements in sleep using carbidopa/ levodopa and propoxyphene. Sleep 1993;16:717-23.

11 Trenkwalder C, Stiasny K, Pollmacher T, et al. L-dopa therapy of uremic and idiopathic restless legs syndrome: a double-blind, crossover trial. Sleep 1995; 18:681-8.

12 Earley CJ, Yaffee JB, Allen RP. Randomized, double-blind, placebo-controlled trial of pergolide in restless legs syndrome. Neurology 1998;51:1599-602.

13 Hening WA, Walters A, Kavey N, et al. Dyskinesias while awake and periodic movements in sleep in restless legs syndrome: treatment with opioids. Neurology 1986;36:1363-6.

14 Walters A, Hening W, Cote L, et al. Dominantly inherited restless legs with myoclonus and periodic movements of sleep: a syndrome related to the endogenous opiates? Adv Neurol 1986;43:309-19.

15 Montplaisir J, Lorrain D, Godbout R. Restless legs syndrome and periodic leg movements in sleep: the primary role of dopaminergic mechanism. Eur Neurol 1991;31:41-3.

16 Kraus T, Schuld A, Pollmacher T. Periodic leg movements in sleep and restless legs syndrome probably caused by olanzapine. J Clin Psychopharmacol 1999; 19:478-9.

17 Wetter TC, Brunner J, Bronisch T. Restless legs syndrome probably induced by risperidone treatment. Pharmacopsychiatry 2002;35:109-11.

18 Winkelmann J, Schadrak J, Thomas CW, et al. Opioid and dopamine antagonist drug challenge in untreated restless legs syndrome patients. Sleep Medicine 2001;2:57-61

19 Colosimo C, Merello M, Albanese A. Clinical usefulness of apomorphine in movement disorders. Clin Neuropharmacol 1994;17:243-59.

20 Dolphin A, Jenner P, Marsden CD, et al. Pharmacological evidence for cerebral dopamine receptor blockade by metoclopramide in rodents. Psychopharmacologia 1975;41:133-8.
21 Gilman AG, Rall TW, Nies AS. Goodman and Gilman's The pharmacological basis of therapeutics, 8th ed. New York: Pergamon Press, 1990.

22 Reuter I, Ellis CM, Ray Chaudhuri K. Nocturnal subcutaneous apomorphine infusion in Parkinson's disease and restless legs syndrome. Acta Neurol Scand 1999;100:163-7.

23 Paradiso G, Khan F, Chen R. Effects of apomorphine on flexor reflex and periodic limb movement. Mov Disord 2002; 17:594-7.

24 Haba-Rubio J, Staner L, Cornette F, et al. Acute low single dose of apomorphine reduces periodic limb movements but has no significant effect on sleep arousals: a preliminary report. Neurophysiol Clin 2003;33:180-4.

25 Priano L, Albani G, Brioschi A, et al. Nocturnal anomalous movement reduction and sleep microstructure analysis in parkinsonian patients during 1night transdermal apomorphine treatment. Neurol Sci 2003;24:207-8.

26 Buysse DJ, Reynolds CF, Monk TH, et al. The Pittsburgh Sleep Quality Index: a new instrument for psychiatric practice and research. Psychiatry Res 1989;28:193-213.

27 Johns MW. A new method for measuring daytime sleepiness: the Epworth sleepiness scale. Sleep 1991;14:540-5.

28 Kaye CM, Nicholls B. Clinical pharmacokinetics of ropinirole. Clin Pharmacokinet 2000:39:243-54.

29 Corsini GU, Del Zompo M, Gessa GL, et al. Therapeutic efficacy of apomorphine combined with an extracerebral inhibitor of dopamine receptors in Parkinson's disease. Lancet, 1979;i, 954-6.

30 Brogden RN, Carmine AA, Heel RC, et al. Domperidone. A review of its pharmacological activity, pharmacokinetics and therapeutic efficacy in the symptomatic treatment of chronic dyspepsia and as an antiemetic. Drugs 1982;24:360-400.

31 Montplaisir J, Boucher S, Nicolas A, et al. Immobilization tests and periodic leg movements in sleep for the diagnosis of restless leg syndrome. Mov Disord $1998 ; 13: 324-9$.

32 Michaud M, Poirier G, Lavigne G, et al. Restless legs syndrome: scoring criteria for leg movements recorded during the suggested immobilization test. Sleep Med 2001;2:317-21.

33 Folstein MF, Luria R. Reliability, validity, and clinical application of the visual analogue mood scale. Psychol Med 1973;3:479-86.

34 Coleman RM. Periodic movements in sleep (nocturnal myoclonus) and restless legs syndrome. In: Guilleminault C, eds. Sleeping and waking disorders: indications and techniques. Menlo Park, CA: Addison-Wesley, 1982:265-95.

35 Atlas Task Force. Recording and scoring leg movements. Sleep 1993;16:748-59

36 Michaud M, Lavigne G, Desautels A, et al. Effects of immobility on sensory and motor symptoms of restless legs syndrome. Mov Disord 2002; 17:1 12-15.

37 Turjanski N, Lees AJ, Brooks DJ. Striatal dopaminergic function in restless legs syndrome: ${ }^{18} \mathrm{~F}$-dopa and ${ }^{11} \mathrm{C}$-raclopride PET studies. Neurology 1999:52:932-7.

38 Ruottinen HM, Partinen M, Hublin C, et al. An FDOPA PET study in patients with periodic limb movement disorder and restless legs syndrome. Neurology 2000:54:502-4.

39 Staedt J, Stoppe G, Kogler A, et al. Dopamine D2 receptor alteration in patients with periodic movements in sleep (nocturnal myoclonus). J Neural Transm Gen Sect 1993;93:71-4.

40 Staedt J, Stoppe G, Kogler A, et al. Nocturnal myoclonus syndrome (periodic movements in sleep) related to central dopamine D2-receptor alteration. Eur Arch Psychiatry Clin Neurosci 1995;245:8-10.

41 Michaud M, Soucy JP, Chabli A, et al. SPECT imaging of striatal pre- and postsynaptic dopaminergic status in restless legs syndrome with periodic leg movements in sleep. J Neurol 2002;249:164-70.

42 Allen RP, Earley CJ. Restless legs syndrome: a review of clinical and pathophysiologic features. J Clin Neurophysiol 2001;18:128-47.

43 Trenkwalder C, Walters AS, Hening WA, et al. Positron emission tomographic studies in restless legs syndrome. Mov Disord 1999; 14:141-5.

44 Eisensehr I, Wetter TC, Linke R, et al. Normal IPT and IBZM SPECT in drug naive and levodopa-treated idiopathic restless legs syndrome. Neurology 2001:57:1307-9.

45 Tribl GG, Asenbaum S, Klosch G, et al. Normal IPT and IBZM SPECT in drug naive and levodopa-treated idiopathic restless legs syndrome. Neurology 2002:59:649-50.

46 Acland KM, Churchyard A, Fletcher $\mathrm{CL}$, et al. Panniculitis in association with apomorphine infusion. Br J Dermatol 1998;138:480-2.

47 Stibe CM, Lees AJ, Kempster PA, et al. Subcutaneous apomorphine in parkinsonian on-off oscillations. Lancet, 1988;i, 403-6.

48 Hughes AJ, Bishop S, Kleedorfer B, et al. Subcutaneous apomorphine in Parkinson's disease: response to chronic administration for up to five years. Mov Disord 1993;8:165-70.

49 Gancher ST, Woodward WR, Boucher B, et al. Peripheral pharmacokinetics of apomorphine in humans. Ann Neurol 1989;26:232-8

50 Hughes AJ, Lees AJ, Stern GM. Apomorphine test to predict dopaminergic responsiveness in parkinsonian syndromes. Lancet 1990;336:32-4. 